\title{
A Strong Convergence Theorem for a Common Fixed Point of Two Sequences of Strictly Pseudocontractive Mappings in Hilbert Spaces and Applications
}

\author{
Kasamsuk Ungchittrakool ${ }^{1,2}$ \\ ${ }^{1}$ Department of Mathematics, Faculty of Science, Naresuan University, Phitsanulok 65000, Thailand \\ ${ }^{2}$ Centre of Excellence in Mathematics, CHE, Si Ayutthaya Road, Bangkok 10400, Thailand
}

Correspondence should be addressed to Kasamsuk Ungchittrakool, kasamsuku@nu.ac.th

Received 17 July 2010; Accepted 27 October 2010

Academic Editor: Chaitan Gupta

Copyright (C 2010 Kasamsuk Ungchittrakool. This is an open access article distributed under the Creative Commons Attribution License, which permits unrestricted use, distribution, and reproduction in any medium, provided the original work is properly cited.

We prove a strong convergence theorem for a common fixed point of two sequences of strictly pseudocontractive mappings in Hilbert spaces. We also provide some applications of the main theorem to find a common element of the set of fixed points of a strict pseudocontraction and the set of solutions of an equilibrium problem in Hilbert spaces. The results extend and improve the recent ones announced by Marino and $\mathrm{Xu}$ (2007) and others.

\section{Introduction}

Let $H$ be a real Hilbert space and $C$ a nonempty closed convex subset of $H$. Let $T: C \rightarrow C$ be a self-mapping of $C$. Recall that $T$ is said to be a strict pseudocontraction if there exists a constant $0 \leqslant k<1$ such that

$$
\|T x-T y\|^{2} \leqslant\|x-y\|+k\|(I-T) x-(I-T) y\|^{2}
$$

for all $x, y \in C$. (We also say that $T$ is a $k$-strict pseudocontraction if $T$ satisfies (1.1)). We use $F(T)$ to denote the set of fixed points of $T$ (i.e., $F(T)=\{x \in C: T x=x\}$ ). Note that the class 
of strict pseudocontractions strictly includes the class of nonexpansive mappings which are mappings $T$ on $C$ such that

$$
\|T x-T y\| \leqslant\|x-y\|
$$

for all $x, y \in C$. That is, $T$ is nonexpansive if and only if $T$ is a 0 -strict pseudocontraction. In 1953, Mann [1] introduced the following iterative scheme:

$$
\begin{gathered}
x_{0} \in C \text { chosen arbitrarily, } \\
x_{n+1}=\alpha_{n} x_{n}+\left(1-\alpha_{n}\right) T x_{n}, \quad n=0,1,2, \ldots,
\end{gathered}
$$

where the sequence $\left\{\alpha_{n}\right\}$ is chosen in [0,1]. Mann's iteration process (1.3) has been extensively investigated for nonexpansive mappings. One of the fundamental convergence results was proved by Reich [2]. In an infinite-dimensional Hilbert space, the Mann's iteration (1.3) can conclude only weak convergence [3, 4]. In 1967, Browder and Petryshyn [5] established the first convergence result for a $k$-strict pseudocontraction in a real Hilbert space. They proved weak and strong convergence theorems by using (1.3) with a constant control sequence $\left\{\alpha_{n}\right\} \equiv \alpha$ for all $n$. However, this scheme has only weak convergence even in a Hilbert space. Therefore, many authors try to modify the normal Mann's iteration process to have strong convergence; see, for example, [6-10] and the references therein.

Attempts to modify (1.3) so that strong convergence is guaranteed have been made. In 2003, Nakajo and Takahashi [9] proposed the following modification of (1.3) for a single nonexpansive mapping $T$ by using the hybrid projection method in a Hilbert space $H$

$$
\begin{gathered}
x_{0} \in C \text { chosen arbitrarily, } \\
y_{n}=\alpha_{n} x_{n}+\left(1-\alpha_{n}\right) T x_{n}, \\
C_{n}=\left\{z \in C:\left\|z-y_{n}\right\| \leqslant\left\|z-x_{n}\right\|\right\}, \\
Q_{n}=\left\{z \in C:\left\langle x_{n}-z, x-x_{n}\right\rangle \geqslant 0\right\}, \\
x_{n+1}=P_{C_{n} \cap Q_{n}}(x), \quad n=0,1,2, \ldots,
\end{gathered}
$$

where $P_{C}$ denotes the metric projection from $H$ onto a closed convex subset $C$ of $H$. They proved that if the sequence $\left\{\alpha_{n}\right\}$ is bounded above from one, then $\left\{x_{n}\right\}$ defined by (1.4) converges strongly to $P_{F(T)}(x)$. 
In 2007, Marino and Xu [11] proved the following strong convergence theorem by using the hybrid projection method for a strict pseudocontraction. They defined a sequence as follows:

$$
\begin{gathered}
x_{0} \in C \text { chosen arbitrarily, } \\
y_{n}=\alpha_{n} x_{n}+\left(1-\alpha_{n}\right) T x_{n}, \\
C_{n}=\left\{z \in C:\left\|y_{n}-z\right\|^{2} \leqslant\left\|x_{n}-z\right\|^{2}+\left(1-\alpha_{n}\right)\left(k-\alpha_{n}\right)\left\|x_{n}-T x_{n}\right\|^{2}\right\}, \\
Q_{n}=\left\{z \in C:\left\langle x_{n}-z, x_{0}-x_{n}\right\rangle \geqslant 0\right\}, \\
x_{n+1}=P_{C_{n} \cap Q_{n}}\left(x_{0}\right), \quad n=0,1,2, \ldots,
\end{gathered}
$$

They proved that if $0 \leqslant \alpha_{n}<1$, then $\left\{x_{n}\right\}$ defined by (1.5) converges strongly to $P_{F(T)}\left(x_{0}\right)$.

Motivated and inspired by the above-mentioned results, it is the purpose of this paper to improve and generalize the algorithm (1.5) to the new general process of two sequences of strictly pseudocontractive mappings in Hilbert spaces. Let $C$ be a closed convex subset of a Hilbert space $H$ and $T_{n}, S_{n}: C \rightarrow C$ two sequences of strictly pseudocontractive mappings such that $\bigcap_{n=0}^{\infty} F\left(T_{n}\right) \cap \bigcap_{n=0}^{\infty} F\left(S_{n}\right) \neq \emptyset$. Define $\left\{x_{n}\right\}$ in the following ways:

$$
\begin{gathered}
x_{0} \in C \text { chosen arbitrarily, } \\
y_{n}=\alpha_{n} x_{n}+\left(1-\alpha_{n}\right) z_{n}, \\
z_{n}=\beta_{n} T_{n} x_{n}+\left(1-\beta_{n}\right) S_{n} x_{n}, \\
\widehat{C}_{n}=\left\{z \in C:\left\|y_{n}-z\right\|^{2} \leqslant\left\|x_{n}-z\right\|^{2}+\left(1-\alpha_{n}\right) \beta_{n}\left(k_{T}^{n}-\alpha_{n}\right)\left\|x_{n}-T_{n} x_{n}\right\|^{2}\right. \\
\left.+\left(1-\alpha_{n}\right)\left(1-\beta_{n}\right)\left(k_{S}^{n}-\alpha_{n}\right)\left\|x_{n}-S_{n} x_{n}\right\|^{2}-\left(1-\alpha_{n}\right)^{2} \beta_{n}\left(1-\beta_{n}\right)\left\|T_{n} x_{n}-S_{n} x_{n}\right\|^{2}\right\}, \\
Q_{n}=\left\{z \in C:\left\langle x_{n}-z, x_{0}-x_{n}\right\rangle \geqslant 0\right\}, \\
x_{n+1}=P_{\widehat{C}_{n} \cap Q_{n}}\left(x_{0}\right),
\end{gathered}
$$

where $\left\{\alpha_{n}\right\},\left\{\beta_{n}\right\}$ are sequences in $[0,1]$.

We prove that the algorithm (1.6) converges strongly to a common fixed point of two sequences of strictly pseudocontractive mappings $\left\{T_{n}\right\}$ and $\left\{S_{n}\right\}$ provided that $\left\{T_{n}\right\},\left\{S_{n}\right\}$, $\left\{\alpha_{n}\right\}$ and $\left\{\beta_{n}\right\}$ satisfy some appropriate conditions, and then we apply the result for finding a common element of the set of fixed points of a strict pseudocontraction and the set of solutions of an equilibrium problem in Hilbert spaces. Our results extend and improve the corresponding ones announced by Marino and $\mathrm{Xu}$ [11] and others.

Throughout the paper, we will use the following notation:

(i) $\rightarrow$ for strong convergence and $\rightarrow$ for weak convergence,

(ii) $\omega_{w}\left(x_{n}\right)=\left\{x: \exists x_{n_{r}} \rightarrow x\right\}$ denotes the weak $\omega$-limit set of $\left\{x_{n}\right\}$. 


\section{Preliminaries}

This section collects some definitions and lemmas which will be used in the proofs for the main results in the next section. Some of them are known; others are not hard to derive.

Lemma 2.1. Let $H$ be a real Hilbert space. There holds the following identity:

(i) $\|x-y\|^{2}=\|x\|^{2}-\|y\|^{2}-2\langle x-y, y\rangle$ for all $x, y \in H$.

(ii) $\|t x+(1-t) y\|^{2}=t\|x\|^{2}+(1-t)\|y\|^{2}-t(1-t)\|x-y\|^{2}$ for all $t \in[0,1]$, for all $x, y \in H$.

Lemma 2.2. Let $H$ be a real Hilbert space. Given a closed convex subset $C \subset H$ and $x, y, z \in H$. Given also a real number $a \in \mathbb{R}$. The set

$$
\left\{v \in C:\|y-v\|^{2} \leqslant\|x-v\|^{2}+\langle z, v\rangle+a\right\}
$$

is convex (and closed).

Recall that given a closed convex subset $C$ of a real Hilbert space $H$, the nearest point projection $P_{C}$ from $H$ onto $C$ assigns to each $x \in H$ its nearest point denoted by $P_{C} x$ which is a unique point in $C$ with the property

$$
\left\|x-P_{C} x\right\| \leqslant\|x-z\| \quad \forall z \in C .
$$

Lemma 2.3. Let $C$ be a closed convex subset of real Hilbert space $H$. Given $x \in H$ and $z \in C$. Then, $z=P_{C} x$ if and only if there holds the relation

$$
\langle x-z, z-y\rangle \geqslant 0 \quad \forall y \in C .
$$

Lemma 2.4 (Martinez-Yanes and $\mathrm{Xu}[8]$ ). Let $\mathrm{C}$ be a closed convex subset of real Hilbert space $H$. Let $\left\{x_{n}\right\}$ be a sequence in $H$ and $u \in H$. Let $q=P_{C} u$. If $\left\{x_{n}\right\}$ is such that $\omega_{w}\left(x_{n}\right) \subset C$ and satisfies the condition

$$
\left\|x_{n}-u\right\| \leqslant\|u-q\| \quad \forall n .
$$

Then, $x_{n} \rightarrow q$.

Given a closed convex subset $C$ of a real Hilbert space $H$ and a mapping $T: C \rightarrow C$. Recall that $T$ is said to be a quasistrict pseudocontraction if $F(T)$ is nonempty and there exists a constant $0 \leqslant k<1$ such that

$$
\|T x-p\|^{2} \leqslant\|x-p\|^{2}+k\|x-T x\|^{2}
$$

for all $x \in C$ and $p \in F(T)$. 
Proposition 2.5 (Marino and Xu [11, Proposition 2.1]). Assume $C$ is a closed convex subset of a Hilbert space $H$, and let $T: C \rightarrow C$ be a self-mapping of $C$.

(i) If $T$ is a $k$-strict pseudocontraction, then $T$ satisfies Lipschitz condition

$$
\|T x-T y\| \leqslant \frac{1+k}{1-k}\|x-y\| \quad \forall x, y \in C .
$$

(ii) If $T$ is a $k$-strict pseudocontraction, then the mapping $I-T$ is demiclosed (at 0 ). That is, if $\left\{x_{n}\right\}$ is a sequence in $C$ such that $x_{n}-\hat{x}$ and $(I-T) x_{n} \rightarrow 0$, then $(I-T) \hat{x}=0$.

(iii) If $T$ is a $k$-quasistrict pseudocontraction, then the fixed-point set $F(T)$ of $T$ is closed and convex so that the projection $P_{F(T)}$ is well defined.

Lemma 2.6 (Plubtieng and Ungchittrakool [12, Lemma 3.1]). Let $C$ be a nonempty subset of a Banach space $E$ and $\left\{T_{n}\right\}$ a sequence of mappings from $C$ into $E$. Suppose that for any bounded subset $B$ of $C$ there exists continuous increasing function $h_{B}$ from $\mathbb{R}^{+}$into $\mathbb{R}^{+}$such that $h_{B}(0)=0$ and

$$
\lim _{k, l \rightarrow \infty} \rho_{l}^{k}=0
$$

where

$$
\rho_{l}^{k}:=\sup \left\{h_{B}\left(\left\|T_{k} z-T_{l} z\right\|\right): z \in B\right\}<\infty,
$$

for all $k, l \in \mathbb{N}$. Then, for each $x \in C,\left\{T_{n} x\right\}$ converges strongly to some point of $E$. Moreover, let $T$ be a mapping from $C$ into $E$ defined by

$$
T x=\lim _{n \rightarrow \infty} T_{n} x \quad \forall x \in C .
$$

Then, $\lim _{n \rightarrow \infty} \sup \left\{h_{B}\left(\left\|T z-T_{n} z\right\|\right): z \in B\right\}=0$.

Lemma 2.7. Let $H$ be a real Hilbert space, let $C$ be a nonempty closed convex subset of $H$, and let $\left\{T_{n}\right\}$ be a sequence such that for each $n, T_{n}$ is $k^{n}$-strict pseudo contraction from $C$ into $H$ with $\limsup _{n \rightarrow \infty} k^{n}<1$ and

$$
T x=\lim _{n \rightarrow \infty} T_{n} x \quad \forall x \in C .
$$

Then, $F(T)$ is closed and convex so that the projection $P_{F(T)}$ is well defined. 
Proof. To see that $F(T)$ is closed, assume that $\left\{p_{n}\right\}$ is a sequence in $F(T)$ such that $p_{n} \rightarrow \hat{p}$. Since $T_{n}$ is a $k^{n}$-quasistrict pseudocontraction, we get, for each $n$,

$$
\begin{aligned}
\left\|T \hat{p}-p_{n}\right\|^{2} & =\left\|T \hat{p}-T p_{n}\right\|^{2}=\left\|\lim _{m \rightarrow \infty} T_{m} \hat{p}-\lim _{m \rightarrow \infty} T_{m} p_{n}\right\|^{2}=\lim _{m \rightarrow \infty}\left\|T_{m} \hat{p}-T_{m} p_{n}\right\|^{2} \\
& \leqslant \limsup _{m \rightarrow \infty}\left(\left\|\hat{p}-p_{n}\right\|^{2}+k^{m}\left\|\left(\hat{p}-T_{m} \hat{p}\right)-\left(p_{n}-T_{m} p_{n}\right)\right\|^{2}\right) \\
& \leqslant\left\|\hat{p}-p_{n}\right\|^{2}+\left(\limsup _{m \rightarrow \infty} k^{m}\right)\left(\limsup _{m \rightarrow \infty}\left\|\left(\hat{p}-T_{m} \hat{p}\right)-\left(p_{n}-T_{m} p_{n}\right)\right\|^{2}\right) \\
& =\left\|\hat{p}-p_{n}\right\|^{2}+\left(\limsup _{m \rightarrow \infty} k^{m}\right)\left\|\left(\hat{p}-\lim _{m \rightarrow \infty} T_{m} \hat{p}\right)-\left(p_{n}-\lim _{m \rightarrow \infty} T_{m} p_{n}\right)\right\|^{2} \\
& =\left\|\hat{p}-p_{n}\right\|^{2}+\left(\limsup _{m \rightarrow \infty} k^{m}\right)\|\hat{p}-T \hat{p}\|^{2} .
\end{aligned}
$$

Taking the limit as $n \rightarrow \infty$ yields $\|T \hat{p}-\hat{p}\|^{2} \leqslant \kappa\|\hat{p}-T \hat{p}\|^{2}$, where $\kappa:=\lim \sup _{m \rightarrow \infty} k^{m}$. Since $0 \leqslant \kappa<1$, we have $T \widehat{p}=\hat{p}$.

\section{Main Result}

In this section, we prove a strong convergence theorem by using the hybrid projection method (some authors call this the $C Q$ method) for finding a common element of the set of fixed points of two sequences of strictly pseudocontractive mappings in Hilbert spaces.

Theorem 3.1. Let $C$ be a closed convex subset of a Hilbert space $H$. For each $n$, let $T_{n}, S_{n}: C \rightarrow C$ be $k_{T}^{n}, k_{S}^{n}$-strict pseudocontractions for some $0 \leqslant k_{T}^{n}, k_{S}^{n}<1$ with $\limsup _{n \rightarrow \infty} k_{T}^{n}, \limsup _{n \rightarrow \infty} k_{S}^{n}<1$, respectively, and assume that $\bigcap_{n=0}^{\infty} F\left(T_{n}\right) \cap \bigcap_{n=0}^{\infty} F\left(S_{n}\right) \neq \emptyset$. Let $\left\{x_{n}\right\}_{n=0}^{\infty}$ be the sequence generated by

$$
\begin{gathered}
x_{0} \in C \text { chosen arbitrarily, } \\
y_{n}=\alpha_{n} x_{n}+\left(1-\alpha_{n}\right) z_{n}, \\
z_{n}=\beta_{n} T_{n} x_{n}+\left(1-\beta_{n}\right) S_{n} x_{n}, \\
\widehat{C}_{n}=\left\{z \in C:\left\|y_{n}-z\right\|^{2} \leqslant\left\|x_{n}-z\right\|^{2}+\left(1-\alpha_{n}\right) \beta_{n}\left(k_{T}^{n}-\alpha_{n}\right)\left\|x_{n}-T_{n} x_{n}\right\|^{2}\right. \\
\left.+\left(1-\alpha_{n}\right)\left(1-\beta_{n}\right)\left(k_{S}^{n}-\alpha_{n}\right)\left\|x_{n}-S_{n} x_{n}\right\|^{2}-\left(1-\alpha_{n}\right)^{2} \beta_{n}\left(1-\beta_{n}\right)\left\|T_{n} x_{n}-S_{n} x_{n}\right\|^{2}\right\}, \\
Q_{n}=\left\{z \in C:\left\langle x_{n}-z, x_{0}-x_{n}\right\rangle \geqslant 0\right\}, \\
x_{n+1}=P_{\widehat{C}_{n} \cap Q_{n}}\left(x_{0}\right) .
\end{gathered}
$$


Assume that $\left\{\alpha_{n}\right\}$ and $\left\{\beta_{n}\right\}$ are chosen so that $0 \leqslant \alpha_{n}<1$ and $0<a \leqslant \beta_{n} \leqslant b<1$ for all $n$. Suppose that for any bounded subset $B$ of $C$ there exists an increasing, continuous, and convex function $h_{B}$ from $\mathbb{R}^{+}$into $\mathbb{R}^{+}$such that $h_{B}(0)=0$, and

$$
\lim _{k, l \rightarrow \infty} \sup \left\{h_{B}\left(\left\|T_{k} z-T_{l} z\right\|\right): z \in B\right\}=0=\lim _{k, l \rightarrow \infty} \sup \left\{h_{B}\left(\left\|S_{k} z-S_{l} z\right\|\right): z \in B\right\} .
$$

Let $T, S: C \rightarrow C$ such that $T x=\lim _{n \rightarrow \infty} T_{n} x$ and $S x=\lim _{n \rightarrow \infty} S_{n} x$ for all $x \in C$, respectively, and suppose that $F(T)=\bigcap_{n=0}^{\infty} F\left(T_{n}\right)$ and $F(S)=\bigcap_{n=0}^{\infty} F\left(S_{n}\right)$. Then, $\left\{x_{n}\right\}$ converges strongly to $a$ common fixed point $q=P_{F(T) \cap F(S)}\left(x_{0}\right)$.

Proof. It is not hard to check that $\widehat{C}_{n}$ and $Q_{n}$ are closed and convex for all $n$ (via Lemma 2.2 and the properties of the inner product). Then, if $\widehat{C}_{n} \cap Q_{n}$ is nonempty for all $n$, the sequence $\left\{x_{n}\right\}$ is well defined. Now, we will show that $\bigcap_{n=0}^{\infty} F\left(T_{n}\right) \cap \bigcap_{n=0}^{\infty} F\left(S_{n}\right) \subset \widehat{C}_{n}$ for all $n$. Let $p \in \bigcap_{n=0}^{\infty} F\left(T_{n}\right) \cap \bigcap_{n=0}^{\infty} F\left(S_{n}\right)$, we observe that

$$
\begin{aligned}
\left\|z_{n}-p\right\|^{2}= & \left\|\beta_{n}\left(T_{n} x_{n}-p\right)+\left(1-\beta_{n}\right)\left(S_{n} x_{n}-p\right)\right\|^{2} \\
= & \beta_{n}\left\|T_{n} x_{n}-p\right\|^{2}+\left(1-\beta_{n}\right)\left\|S_{n} x_{n}-p\right\|^{2}-\beta_{n}\left(1-\beta_{n}\right)\left\|T_{n} x_{n}-S_{n} x_{n}\right\|^{2} \\
\leqslant & \beta_{n}\left(\left\|x_{n}-p\right\|^{2}+k_{T}^{n}\left\|x_{n}-T_{n} x_{n}\right\|^{2}\right)+\left(1-\beta_{n}\right)\left(\left\|x_{n}-p\right\|^{2}+k_{S}^{n}\left\|x_{n}-S_{n} x_{n}\right\|^{2}\right) \\
& -\beta_{n}\left(1-\beta_{n}\right)\left\|T_{n} x_{n}-S_{n} x_{n}\right\|^{2} \\
= & \left\|x_{n}-p\right\|^{2}+\beta_{n} k_{T}^{n}\left\|x_{n}-T_{n} x_{n}\right\|^{2}+\left(1-\beta_{n}\right) k_{S}^{n}\left\|x_{n}-S_{n} x_{n}\right\|^{2} \\
& -\beta_{n}\left(1-\beta_{n}\right)\left\|T_{n} x_{n}-S_{n} x_{n}\right\|^{2}, \\
\left\|x_{n}-z_{n}\right\|^{2}= & \left\|\beta_{n}\left(x_{n}-T_{n} x_{n}\right)+\left(1-\beta_{n}\right)\left(x_{n}-S_{n} x_{n}\right)\right\|^{2} \\
= & \beta_{n}\left\|x_{n}-T_{n} x_{n}\right\|^{2}+\left(1-\beta_{n}\right)\left\|x_{n}-S_{n} x_{n}\right\|^{2}-\beta_{n}\left(1-\beta_{n}\right)\left\|T_{n} x_{n}-S_{n} x_{n}\right\|^{2} .
\end{aligned}
$$

By (3.3) and (3.4) we obtain

$$
\begin{aligned}
\left\|y_{n}-p\right\|^{2}= & \left\|\alpha_{n}\left(x_{n}-p\right)+\left(1-\alpha_{n}\right)\left(z_{n}-p\right)\right\|^{2} \\
= & \alpha_{n}\left\|x_{n}-p\right\|^{2}+\left(1-\alpha_{n}\right)\left\|z_{n}-p\right\|^{2}-\alpha_{n}\left(1-\alpha_{n}\right)\left\|x_{n}-z_{n}\right\|^{2} \\
\leqslant & \left\|x_{n}-p\right\|^{2}+\left(1-\alpha_{n}\right) \beta_{n}\left(k_{T}^{n}-\alpha_{n}\right)\left\|x_{n}-T_{n} x_{n}\right\|^{2} \\
& +\left(1-\alpha_{n}\right)\left(1-\beta_{n}\right)\left(k_{S}^{n}-\alpha_{n}\right)\left\|x_{n}-S_{n} x_{n}\right\|^{2} \\
& -\left(1-\alpha_{n}\right)^{2} \beta_{n}\left(1-\beta_{n}\right)\left\|T_{n} x_{n}-S_{n} x_{n}\right\|^{2} .
\end{aligned}
$$


Thus, we have $F(T) \cap F(S) \subset \widehat{C}_{n}$ for all $n$. Next, we will show that $F(T) \cap F(S) \subset Q_{n}$ for all $n$. If $n=0$, then $F(T) \cap F(S) \subset C=Q_{0}$. Assume that $F(T) \cap F(S) \subset Q_{n}$. Since $x_{n+1}$ is the projection of $x_{0}$ onto $\widehat{C}_{n} \cap Q_{n}$, by Lemma 2.3 we have

$$
\left\langle x_{n+1}-z, x_{0}-x_{n+1}\right\rangle \geqslant 0 \quad \forall z \in \widehat{C}_{n} \cap Q_{n}
$$

Noting that $F(T) \cap F(S) \subset \widehat{C}_{n} \cap Q_{n}$ by the induction assumption, it implies that $F(T) \cap F(S) \subset$ $Q_{n+1}$, thus by induction $F(T) \cap F(S) \subset Q_{n}$ for all $n$. Hence, $F(T) \cap F(S) \subset \widehat{C}_{n} \cap Q_{n}$ for all $n$. So, $\left\{x_{n}\right\}$ is well defined.

Notice that the definition of $Q_{n}$ actually implies $x_{n}=P_{Q_{n}}\left(x_{0}\right)$. This together with the fact $F(T) \cap F(S) \subset Q_{n}$ further implies

$$
\left\|x_{n}-x_{0}\right\| \leqslant\left\|p-x_{0}\right\| \quad \forall p \in F(T) \cap F(S) .
$$

In particular, $\left\{x_{n}\right\}$ is bounded and

$$
\left\|x_{n}-x_{0}\right\| \leqslant\left\|q-x_{0}\right\| \quad \forall n,
$$

where $q=P_{F(T) \cap F(S)}\left(x_{0}\right)$.

The fact $x_{n+1} \in Q_{n}$ asserts that $\left\langle x_{n+1}-x_{n}, x_{n}-x_{0}\right\rangle \geqslant 0$. This together with Lemma 2.1(i) and Lemma 2.3 implies

$$
\begin{aligned}
\left\|x_{n+1}-x_{n}\right\|^{2} & =\left\|\left(x_{n+1}-x_{0}\right)-\left(x_{n}-x_{0}\right)\right\|^{2} \\
& =\left\|x_{n+1}-x_{0}\right\|^{2}-\left\|x_{n}-x_{0}\right\|^{2}-2\left\langle x_{n+1}-x_{n}, x_{n}-x_{0}\right\rangle \\
& \leqslant\left\|x_{n+1}-x_{0}\right\|^{2}-\left\|x_{n}-x_{0}\right\|^{2} .
\end{aligned}
$$

It turns out that

$$
\left\|x_{n+1}-x_{n}\right\| \longrightarrow 0
$$

By the fact $x_{n+1} \in \widehat{C}_{n}$, we get

$$
\begin{aligned}
\left\|x_{n+1}-y_{n}\right\|^{2} \leqslant & \left\|x_{n+1}-x_{n}\right\|^{2}+\left(1-\alpha_{n}\right) \beta_{n}\left(k_{T}^{n}-\alpha_{n}\right)\left\|x_{n}-T_{n} x_{n}\right\|^{2} \\
& +\left(1-\alpha_{n}\right)\left(1-\beta_{n}\right)\left(k_{S}^{n}-\alpha_{n}\right)\left\|x_{n}-S_{n} x_{n}\right\|^{2} \\
& -\left(1-\alpha_{n}\right)^{2} \beta_{n}\left(1-\beta_{n}\right)\left\|T_{n} x_{n}-S_{n} x_{n}\right\|^{2} .
\end{aligned}
$$


Observe that

$$
\begin{aligned}
\left\|x_{n+1}-y_{n}\right\|^{2} & =\left\|\alpha_{n}\left(x_{n+1}-x_{n}\right)+\left(1-\alpha_{n}\right)\left(x_{n}-z_{n}\right)\right\|^{2} \\
& =\alpha_{n}\left\|x_{n+1}-x_{n}\right\|^{2}+\left(1-\alpha_{n}\right)\left\|x_{n+1}-z_{n}\right\|^{2}-\alpha_{n}\left(1-\alpha_{n}\right)\left\|x_{n}-z_{n}\right\|^{2} \\
\left\|x_{n+1}-z_{n}\right\|^{2} & =\left\|\beta_{n}\left(x_{n+1}-T_{n} x_{n}\right)+\left(1-\beta_{n}\right)\left(x_{n+1}-S_{n} x_{n}\right)\right\|^{2} \\
& =\beta_{n}\left\|x_{n+1}-T_{n} x_{n}\right\|^{2}+\left(1-\beta_{n}\right)\left\|x_{n+1}-S_{n} x_{n}\right\|^{2}-\beta_{n}\left(1-\beta_{n}\right)\left\|T_{n} x_{n}-S_{n} x_{n}\right\|^{2} .
\end{aligned}
$$

With simple calculation by using (3.12) and (3.4), we have

$$
\begin{aligned}
\left\|x_{n+1}-y_{n}\right\|^{2}= & \alpha_{n}\left\|x_{n+1}-x_{n}\right\|^{2}+\left(1-\alpha_{n}\right) \beta_{n}\left\|x_{n+1}-T_{n} x_{n}\right\|^{2} \\
& +\left(1-\alpha_{n}\right)\left(1-\beta_{n}\right)\left\|x_{n+1}-S_{n} x_{n}\right\|^{2}-\alpha_{n}\left(1-\alpha_{n}\right) \beta_{n}\left\|x_{n}-T_{n} x_{n}\right\|^{2} \\
& -\alpha_{n}\left(1-\alpha_{n}\right)\left(1-\beta_{n}\right)\left\|x_{n}-S_{n} x_{n}\right\|^{2}-\left(1-\alpha_{n}\right)^{2} \beta_{n}\left(1-\beta_{n}\right)\left\|T_{n} x_{n}-S_{n} x_{n}\right\|^{2} .
\end{aligned}
$$

So, when we combine (3.11) and (3.13) and compute, we obtain

$$
\begin{aligned}
& \left(1-\alpha_{n}\right) \beta_{n}\left\|x_{n+1}-T_{n} x_{n}\right\|^{2}+\left(1-\alpha_{n}\right)\left(1-\beta_{n}\right)\left\|x_{n+1}-S_{n} x_{n}\right\|^{2} \\
& \quad \leqslant\left(1-\alpha_{n}\right)\left\|x_{n+1}-x_{n}\right\|^{2}+\left(1-\alpha_{n}\right) \beta_{n} k_{T}^{n}\left\|x_{n}-T_{n} x_{n}\right\|^{2}+\left(1-\alpha_{n}\right)\left(1-\beta_{n}\right) k_{S}^{n}\left\|x_{n}-S_{n} x_{n}\right\|^{2} .
\end{aligned}
$$

Since $\alpha_{n}<1$ for all $n$, we have

$$
\begin{aligned}
& \beta_{n}\left\|x_{n+1}-T_{n} x_{n}\right\|^{2}+\left(1-\beta_{n}\right)\left\|x_{n+1}-S_{n} x_{n}\right\|^{2} \\
& \quad \leqslant\left\|x_{n+1}-x_{n}\right\|^{2}+\beta_{n} k_{T}^{n}\left\|x_{n}-T_{n} x_{n}\right\|^{2}+\left(1-\beta_{n}\right) k_{S}^{n}\left\|x_{n}-S_{n} x_{n}\right\|^{2} .
\end{aligned}
$$

Notice that

$$
\begin{aligned}
\left\|x_{n+1}-T_{n} x_{n}\right\|^{2} & =\left\|\left(x_{n+1}-x_{n}\right)+\left(x_{n}-T_{n} x_{n}\right)\right\|^{2} \\
& =\left\|x_{n+1}-x_{n}\right\|^{2}+2\left\langle x_{n+1}-x_{n}, x_{n}-T_{n} x_{n}\right\rangle+\left\|x_{n}-T_{n} x_{n}\right\|^{2}, \\
\left\|x_{n+1}-S_{n} x_{n}\right\|^{2} & =\left\|\left(x_{n+1}-x_{n}\right)+\left(x_{n}-S_{n} x_{n}\right)\right\|^{2} \\
& =\left\|x_{n+1}-x_{n}\right\|^{2}+2\left\langle x_{n+1}-x_{n}, x_{n}-S_{n} x_{n}\right\rangle+\left\|x_{n}-S_{n} x_{n}\right\|^{2} .
\end{aligned}
$$

By (3.15), (3.16), and (3.17), we have

$$
\begin{aligned}
& \beta_{n}\left(1-k_{T}^{n}\right)\left\|x_{n}-T_{n} x_{n}\right\|^{2}+\left(1-\beta_{n}\right)\left(1-k_{S}^{n}\right)\left\|x_{n}-S_{n} x_{n}\right\|^{2} \\
& \quad \leqslant-2 \beta_{n}\left\langle x_{n+1}-x_{n}, x_{n}-T_{n} x_{n}\right\rangle-2\left(1-\beta_{n}\right)\left\langle x_{n+1}-x_{n}, x_{n}-S_{n} x_{n}\right\rangle .
\end{aligned}
$$


Since $\left\{x_{n}\right\},\left\{T_{n} x_{n}\right\}$, and $\left\{S_{n} x_{n}\right\}$ are bounded, $0<a \leqslant \beta_{n} \leqslant b<1$ for all $n$ and $\lim \sup _{n \rightarrow \infty} k_{T^{\prime}}^{n}$ $\lim \sup _{n \rightarrow \infty} k_{S}^{n}<1$, it follows from (3.10) and (3.18) that

$$
\lim _{n \rightarrow \infty}\left\|x_{n}-T_{n} x_{n}\right\|=0=\lim _{n \rightarrow \infty}\left\|x_{n}-S_{n} x_{n}\right\|
$$

Since $\left\{x_{n}\right\}$ is bounded, there exists a bounded subset $B$ of $C$ such that $\left\{x_{n}\right\} \subset B$. From Lemma 2.6, we are able to set $T x=\lim _{m \rightarrow \infty} T_{m} x$ for all $x \in C$, and then observe that

$$
\frac{1}{2}\left\|x_{n}-T x_{n}\right\| \leqslant \frac{1}{2}\left\|x_{n}-T_{n} x_{n}\right\|+\frac{1}{2}\left\|T_{n} x_{n}-T x_{n}\right\| .
$$

Since $h_{B}$ is an increasing, continuous, and convex function from $\mathbb{R}^{+}$into $\mathbb{R}^{+}$such that $h_{B}(0)=$ 0 , we discover that

$$
\begin{aligned}
h_{B}\left(\frac{1}{2}\left\|x_{n}-T x_{n}\right\|\right) & \leqslant \frac{1}{2} h_{B}\left(\left\|x_{n}-T_{n} x_{n}\right\|\right)+\frac{1}{2} h_{B}\left(\left\|T_{n} x_{n}-T x_{n}\right\|\right) \\
& \leqslant \frac{1}{2} h_{B}\left(\left\|x_{n}-T_{n} x_{n}\right\|\right)+\frac{1}{2} \sup \left\{h_{B}\left(\left\|T_{n} z-T z\right\|\right): z \in B\right\} .
\end{aligned}
$$

By Lemma 2.6 and the continuity of $h_{B}$, we have $\lim _{n \rightarrow \infty} h_{B}\left((1 / 2)\left\|x_{n}-T x_{n}\right\|\right)=0$. And then the properties of $h_{B}$ yield

$$
\lim _{n \rightarrow \infty}\left\|x_{n}-T x_{n}\right\|=0
$$

By the same argument, we have

$$
\lim _{n \rightarrow \infty}\left\|x_{n}-S x_{n}\right\|=0 .
$$

Now Proposition 2.5 guarantees that $\omega_{w}\left(x_{n}\right) \subset F(T) \cap F(S)$. This fact, the inequality (3.8), and Lemma 2.4 ensure the strong convergence of $\left\{x_{n}\right\}$ to $q=P_{F(T) \cap F(S)}\left(x_{0}\right)$.

If $T_{n}=T$ and $S_{n}=S$ for all $n$, then $k_{T}^{n}=k_{T}$ and $k_{S}^{n}=k_{S}$ for all $n$. So, Theorem 3.1 reduces to the following corollary. 
Corollary 3.2. Let $C$ be a closed convex subset of a Hilbert space $H$. Let $T, S: C \rightarrow C$ be $k_{T}, k_{S^{-}}$ strict pseudocontractions for some $0 \leqslant k_{T}, k_{S}<1$, respectively, and assume that $F(T) \cap F(S) \neq \emptyset$. Let $\left\{x_{n}\right\}_{n=0}^{\infty}$ be the sequence generated by

$$
\begin{gathered}
x_{0} \in C \text { chosen arbitrarily, } \\
y_{n}=\alpha_{n} x_{n}+\left(1-\alpha_{n}\right) z_{n}, \\
z_{n}=\beta_{n} T x_{n}+\left(1-\beta_{n}\right) S x_{n}, \\
\widehat{C}_{n}=\left\{z \in C:\left\|y_{n}-z\right\|^{2} \leqslant\left\|x_{n}-z\right\|^{2}+\left(1-\alpha_{n}\right) \beta_{n}\left(k_{T}-\alpha_{n}\right)\left\|x_{n}-T x_{n}\right\|^{2}\right. \\
\left.+\left(1-\alpha_{n}\right)\left(1-\beta_{n}\right)\left(k_{S}-\alpha_{n}\right)\left\|x_{n}-S x_{n}\right\|^{2}-\left(1-\alpha_{n}\right)^{2} \beta_{n}\left(1-\beta_{n}\right)\left\|T x_{n}-S x_{n}\right\|^{2}\right\}, \\
Q_{n}=\left\{z \in C:\left\langle x_{n}-z, x_{0}-x_{n}\right\rangle \geqslant 0\right\}, \\
x_{n+1}=P_{\widehat{C}_{n} \cap Q_{n}}\left(x_{0}\right),
\end{gathered}
$$

where $\left\{\alpha_{n}\right\}$ and $\left\{\beta_{n}\right\}$ be as in Theorem 3.1. Then, $\left\{x_{n}\right\}$ converges strongly to a common fixed point $q=P_{F(T) \cap F(S)}\left(x_{0}\right)$.

In particular, if $T=S$, then $z_{n}=T x_{n}$ and

$$
\begin{aligned}
\widehat{C}_{n}= & \left\{z \in C:\left\|y_{n}-p\right\|^{2} \leqslant\left\|x_{n}-p\right\|^{2}+\left(1-\alpha_{n}\right) \beta_{n}\left(k_{T}-\alpha_{n}\right)\left\|x_{n}-T x_{n}\right\|^{2}\right. \\
& \left.\quad+\left(1-\alpha_{n}\right)\left(1-\beta_{n}\right)\left(k_{T}-\alpha_{n}\right)\left\|x_{n}-T x_{n}\right\|^{2}-\left(1-\alpha_{n}\right)^{2} \beta_{n}\left(1-\beta_{n}\right)\left\|T x_{n}-T x_{n}\right\|^{2}\right\} \\
= & C_{n} .
\end{aligned}
$$

So, Corollary 3.2 reduces to the following corollary.

Corollary 3.3 (Marino and $\mathrm{Xu}$ [11, Theorem 4.1]). Let $C$ be a closed convex subset of a Hilbert space $H$. Let $T: C \rightarrow C$ be a $k$-strict pseudocontraction for some $0 \leqslant k<1$, and assume that the fixed-point set $F(T) \neq \emptyset$. Let $\left\{x_{n}\right\}_{n=0}^{\infty}$ be the sequence generated by

$$
\begin{gathered}
x_{0} \in C \text { chosen arbitrarily, } \\
y_{n}=\alpha_{n} x_{n}+\left(1-\alpha_{n}\right) T x_{n}, \\
C_{n}=\left\{z \in C:\left\|y_{n}-z\right\|^{2} \leqslant\left\|x_{n}-z\right\|^{2}+\left(1-\alpha_{n}\right)\left(k-\alpha_{n}\right)\left\|x_{n}-T x_{n}\right\|^{2}\right\} \\
Q_{n}=\left\{z \in C:\left\langle x_{n}-z, x_{0}-x_{n}\right\rangle \geqslant 0\right\}, \\
x_{n+1}=P_{C_{n} \cap Q_{n}}\left(x_{0}\right) .
\end{gathered}
$$

Assume that the control sequence $\left\{\alpha_{n}\right\}_{n=0}^{\infty}$ is chosen so that $0 \leqslant \alpha_{n}<1$ for all $n$. Then, $\left\{x_{n}\right\}$ converges strongly to a fixed-point $q=P_{F(T)}\left(x_{0}\right)$.

If $T_{n}=T$ for all $n$ and $\left\{S_{n}\right\}$ is a sequences of nonexpansive mappings, then $k_{T}^{n}=k$ and $k_{S}^{n}=0$ for all $n$. So, Theorem 3.1 reduces to the following corollary. 
Corollary 3.4. Let $C$ be a closed convex subset of a Hilbert space $H$. Let $T: C \rightarrow C$ be a $k$-strict pseudocontraction for some $0 \leqslant k<1$, for each $n$ and $S_{n}: C \rightarrow C$ a nonexpansive mapping, and assume that $F(T) \cap \bigcap_{n=0}^{\infty} F\left(S_{n}\right) \neq \emptyset$. Let $\left\{x_{n}\right\}_{n=0}^{\infty}$ be the sequence generated by

$$
\begin{gathered}
x_{0} \in C \text { chosen arbitrarily, } \\
y_{n}=\alpha_{n} x_{n}+\left(1-\alpha_{n}\right) z_{n}, \\
z_{n}=\beta_{n} T x_{n}+\left(1-\beta_{n}\right) S_{n} x_{n} \\
\widehat{C}_{n}=\left\{z \in C:\left\|y_{n}-z\right\|^{2} \leqslant\left\|x_{n}-z\right\|^{2}+\left(1-\alpha_{n}\right) \beta_{n}\left(k-\alpha_{n}\right)\left\|x_{n}-T x_{n}\right\|^{2}\right. \\
\left.-\alpha_{n}\left(1-\alpha_{n}\right)\left(1-\beta_{n}\right)\left\|x_{n}-S_{n} x_{n}\right\|^{2}-\left(1-\alpha_{n}\right)^{2} \beta_{n}\left(1-\beta_{n}\right)\left\|T x_{n}-S_{n} x_{n}\right\|^{2}\right\}, \\
Q_{n}=\left\{z \in C:\left\langle x_{n}-z, x_{0}-x_{n}\right\rangle \geqslant 0\right\} \\
x_{n+1}=P_{\widehat{C}_{n} \cap Q_{n}}\left(x_{0}\right),
\end{gathered}
$$

where $\left\{\alpha_{n}\right\}$ and $\left\{\beta_{n}\right\}$ be as in Theorem 3.1. Suppose that for any bounded subset $B$ of $C$ there exists an increasing, continuous, and convex function $h_{B}$ from $\mathbb{R}^{+}$into $\mathbb{R}^{+}$such that $h_{B}(0)=0$, and

$$
\lim _{k, l \rightarrow \infty} \sup \left\{h_{B}\left(\left\|S_{k} z-S_{l} z\right\|\right): z \in B\right\}=0 .
$$

Let $S: C \rightarrow C$ be such that $S x=\lim _{n \rightarrow \infty} S_{n} x$ for all $x \in C$, and suppose $F(S)=\bigcap_{n=0}^{\infty} F\left(S_{n}\right)$. Then, $\left\{x_{n}\right\}$ converges strongly to a common fixed point $q=P_{F(T) \cap F(S)}\left(x_{0}\right)$.

\section{Equilibrium Problem}

In this section, we have an application of the main result for finding a common element of the set of fixed points of a strict pseudocontraction and the set of solutions of an equilibrium problem.

Let $H$ be a real Hilbert space, and let $C$ be a nonempty closed convex subset of $H$. Let $\varphi$ be a bifunction of $C \times C$ into $\mathbb{R}$, where $\mathbb{R}$ is the set of real numbers. The equilibrium problem for $\varphi: C \times C \rightarrow \mathbb{R}$ is to find $x \in C$ such that

$$
\varphi(x, y) \geqslant 0 \quad \forall y \in C
$$

The set of solution of (4.1) is denoted by $\operatorname{EP}(\varphi)(=\{x \in C: \varphi(x, y) \geqslant 0$ for all $y \in C\})$. Many problems in physics, optimization, and economics reduce to find some elements of $\operatorname{EP}(\varphi)$. 
For solving the equilibrium problem for a bifunction $\varphi: C \times C \rightarrow \mathbb{R}$, let us assume that $\varphi$ satisfies the following conditions:

(A1) $\varphi(x, x)=0$ for all $x \in C$;

(A2) $\varphi$ is monotone, that is, $\varphi(x, y)+\varphi(y, x) \leqslant 0$ for all $x, y \in C$;

(A3) for each $x, y, z \in C$,

$$
\lim _{t \downarrow 0} \varphi(t z+(1-t) x, y) \leqslant \varphi(x, y)
$$

(A4) for each $x \in C, y \mapsto \varphi(x, y)$ is convex and lower semicontinuous.

The following lemma appears implicitly in [13].

Lemma 4.1 (Blum and Oettli [13]). Let $C$ be a nonempty closed convex subset of $H$, and let $\varphi$ be a bifunction of $C \times C$ into $\mathbb{R}$ satisfying (A1)-(A4). Let $r>0$ and $x \in H$. Then, there exists $z \in C$ such that

$$
\varphi(z, y)+\frac{1}{r}\langle y-z, z-x\rangle \geqslant 0 \quad \forall y \in C .
$$

The following lemma was also given in [14].

Lemma 4.2 (Combettes and Hirstoaga [14]). Assume that $\varphi: C \times C \rightarrow \mathbb{R}$ satisfies (A1)-(A4). For $r>0$ and $x \in H$, define a mapping $S_{r}: H \rightarrow C$ as follows:

$$
S_{r}(x)=\left\{z \in C: \varphi(z, y)+\frac{1}{r}\langle y-z, z-x\rangle \geqslant 0, \forall y \in C\right\}
$$

for all $z \in H$. Then, the following hold:

(1) $S_{r}$ is single-valued;

(2) $S_{r}$ is firmly nonexpansive, that is, for any $x, y \in H,\left\|S_{r} x-S_{r} y\right\|^{2} \leqslant\left\langle S_{r} x-S_{r} y, x-y\right\rangle$;

(3) $F\left(S_{r}\right)=E P(\varphi)$;

(4) $\mathrm{EP}(\varphi)$ is closed and convex.

The following corollary is an application of Corollary 3.4 in the case of finding a common element of the set of fixed points of a strict pseudocontraction and the set of solutions of an equilibrium problem.

Corollary 4.3. Let $C$ be a closed convex subset of a Hilbert space $H$. Let $T: C \rightarrow C$ be a $k$-strict pseudocontraction for some $0 \leqslant k<1$ and $\varphi$ a bifunction from $C \times C$ into $\mathbb{R}$ satisfying (A1)-(A4). 
Suppose that $F(T) \cap E P(\varphi) \neq \emptyset$. Let $\left\{x_{n}\right\}_{n=0}^{\infty}$ be the sequence generated by

$$
\begin{gathered}
x_{0} \in C \text { chosen arbitrarily, } \\
y_{n}=\alpha_{n} x_{n}+\left(1-\alpha_{n}\right) z_{n}, \\
z_{n}=\beta_{n} T x_{n}+\left(1-\beta_{n}\right) u_{n}, \\
u_{n} \in C \text { such that } \varphi\left(u_{n}, y\right)+\frac{1}{r_{n}}\left\langle y-u_{n}, u_{n}-x_{n}\right\rangle \geqslant 0, \forall y \in C, \\
\widehat{C}_{n}=\left\{z \in C:\left\|y_{n}-z\right\|^{2} \leqslant\left\|x_{n}-z\right\|^{2}+\left(1-\alpha_{n}\right) \beta_{n}\left(k-\alpha_{n}\right)\left\|x_{n}-T x_{n}\right\|^{2}\right. \\
\left.-\alpha_{n}\left(1-\alpha_{n}\right)\left(1-\beta_{n}\right)\left\|x_{n}-u_{n}\right\|^{2}-\left(1-\alpha_{n}\right)^{2} \beta_{n}\left(1-\beta_{n}\right)\left\|T x_{n}-u_{n}\right\|^{2}\right\}, \\
Q_{n}=\left\{z \in C:\left\langle x_{n}-z, x_{0}-x_{n}\right\rangle \geqslant 0\right\}, \\
x_{n+1}=P_{\widehat{C}_{n} \cap Q_{n}}\left(x_{0}\right),
\end{gathered}
$$

where $\left\{\alpha_{n}\right\}$ and $\left\{\beta_{n}\right\}$ be as in Theorem 3.1 and $\left\{r_{n}\right\}_{n=0}^{\infty}$ is chosen so that $\left\{r_{n}\right\} \subset(0, \infty)$ with $\inf _{n} r_{n}>0$ and $\sum_{n=0}^{\infty}\left|r_{n+1}-r_{n}\right|<\infty$. Then, $\left\{x_{n}\right\}$ converges strongly to a common fixed point $q=P_{F(T) \cap E P(\varphi)}\left(x_{0}\right)$.

Proof. Obviously, $u_{n}=S_{r_{n}} x_{n}$, where $S_{r_{n}}$ are mappings as in Lemma 4.2. Next, we want to show that for any bounded subset $B$ of $C$ there exists an increasing, continuous, and convex function $h_{B}\left(=(\cdot)^{2}\right)$ from $\mathbb{R}^{+}$into $\mathbb{R}^{+}$such that $h_{B}(0)=0$, and

$$
\lim _{k, l \rightarrow \infty} \sup \left\{h_{B}\left(\left\|S_{r_{k}} v-S_{r_{l}} v\right\|\right): v \in B\right\}=0 .
$$

Let $B$ be a bounded subset of $C$. For each $v \in B$, let $v_{n}=S_{r_{n}} v$. Then, by Lemma 4.2, we have

$$
\begin{gathered}
\varphi\left(v_{l}, y\right)+\frac{1}{r_{l}}\left\langle y-v_{l}, v_{l}-v\right\rangle \geqslant 0 \quad \forall y \in C, \\
\varphi\left(v_{k}, y\right)+\frac{1}{r_{k}}\left\langle y-v_{k}, v_{k}-v\right\rangle \geqslant 0 \quad \forall y \in C .
\end{gathered}
$$

Put $y=v_{k}$ in (4.7) and $y=v_{l}$ in (4.8), we have

$$
\varphi\left(v_{l}, v_{k}\right)+\frac{1}{r_{l}}\left\langle v_{k}-v_{l}, v_{l}-v\right\rangle \geqslant 0, \quad \varphi\left(v_{k}, v_{l}\right)+\frac{1}{r_{k}}\left\langle v_{l}-v_{k}, v_{k}-v\right\rangle \geqslant 0
$$

So, from (A2), we have $\left\langle v_{k}-v_{l},\left(v_{l}-v\right) / r_{l}-\left(v_{k}-v\right) / r_{k}\right\rangle \geqslant 0$ and hence $\left\langle v_{k}-v_{l}, v_{l}-v-\right.$ $\left.\left(r_{l} / r_{k}\right)\left(v_{k}-v\right)\right\rangle \geqslant 0$. Thus,

$$
\left\langle v_{k}-v_{l}, v_{l}-v_{k}\right\rangle+\left\langle v_{k}-v_{l},\left(1-\frac{r_{l}}{r_{k}}\right)\left(v_{k}-v\right)\right\rangle \geqslant 0
$$


Let $b:=\inf _{n} r_{n}$. Thus, we have

$$
\begin{aligned}
\left(\left\|S_{r_{k}} v-S_{r_{l}} v\right\|\right)^{2} & =\left\langle v_{k}-v_{l}, v_{k}-v_{l}\right\rangle \\
& \leqslant\left\langle v_{k}-v_{l},\left(1-\frac{r_{l}}{r_{k}}\right)\left(v_{k}-v\right)\right\rangle \\
& \leqslant\left\|v_{k}-v_{l}\right\| \frac{1}{b}\left|r_{k}-r_{l}\right|\left\|v_{k}-v\right\| \\
& =\frac{1}{b}\left\|S_{r_{k}} v-S_{r_{l}} v\right\|\left\|S_{r_{k}} v-v\right\||| r_{k}-r_{l} \mid \\
& \leqslant \frac{4}{b}\|v-p\|\left|r_{k}-r_{l}\right| \quad \text { where } p \in \operatorname{EP}(\varphi) \\
& \leqslant \frac{4}{b} M\left|r_{k}-r_{l}\right| \quad \text { where } M:=\sup \{\|v-p\|: v \in B\} .
\end{aligned}
$$

Put $k>l$. Observe that

$$
\left(\left\|S_{r_{k}} v-S_{r_{l}} v\right\|\right)^{2} \leqslant \frac{4}{b} M\left|r_{k}-r_{l}\right| \leqslant \frac{4}{b} M \sum_{n=l}^{k-1}\left|r_{n+1}-r_{n}\right| \leqslant \frac{4}{b} M \sum_{n=l}^{\infty}\left|r_{n+1}-r_{n}\right|<\infty,
$$

for all $v \in B$, and then

$$
\rho_{l}^{k}=\sup \left\{\left(\left\|S_{r_{k}} v-S_{r_{l}} v\right\|\right)^{2}: v \in B\right\} \leqslant \frac{4}{b} M \sum_{n=l}^{\infty}\left|r_{n+1}-r_{n}\right|<\infty
$$

Let $l \rightarrow \infty$, we have $\lim _{k, l \rightarrow \infty} \rho_{l}^{k}=0$. Then, by Lemma 2.6, we can define a mapping $S$ by

$$
S x=\lim _{n \rightarrow \infty} S_{r_{n}} x \quad \forall x \in C .
$$

Next, we will show that

$$
F(S)=\bigcap_{n=0}^{\infty} F\left(S_{r_{n}}\right)=\mathrm{EP}(\varphi)
$$

Since $\left\{r_{n}\right\} \subset(0, \infty), \inf _{n} r_{n}>0$ and (4.14), it is easy to see that

$$
\mathrm{EP}(\varphi)=\bigcap_{n=0}^{\infty} F\left(S_{r_{n}}\right) \subset F(S)
$$

Let $p \in F(S)$. By the definition of $S_{r}$, we have

$$
\varphi\left(S_{r_{n}} p, y\right)+\frac{1}{r_{n}}\left\langle y-S_{r_{n}} p, S_{r_{n}} p-p\right\rangle \geqslant 0 \quad \forall y \in C .
$$


By (A2), we have

$$
\frac{1}{r_{n}}\left\langle y-S_{r_{n}} p, S_{r_{n}} p-p\right\rangle \geqslant \varphi\left(y, S_{r_{n}} p\right) \quad \forall y \in C
$$

From (4.14) and the lower semicontinuity of $\varphi(y, \cdot)$, we have $0 \geqslant \varphi(y, p)$ for all $y \in C$. Let $y \in C$ and set $x_{t}=t y+(1-t) p$, for $t \in(0,1]$. Then, we have

$$
0=\varphi\left(x_{t}, x_{t}\right) \leqslant t \varphi\left(x_{t}, y\right)+(1-t) \varphi\left(x_{t}, p\right) \leqslant t \varphi\left(x_{t}, y\right) .
$$

So $\varphi\left(x_{t}, y\right) \geqslant 0$. Letting $t \downarrow 0$ and using (A3), we get $\varphi(p, y) \geqslant 0$ for all $y \in C$, and hence $p \in \operatorname{EP}(\varphi)=\bigcap_{n=1}^{\infty} F\left(S_{r_{n}}\right)$. Hence, we have (4.15). Then, applying Corollary 3.4, $x_{n} \rightarrow q=$ $P_{F(T) \cap \operatorname{EP}(\varphi)}\left(x_{0}\right)$.

\section{Acknowledgments}

This research is supported by the Centre of Excellence in Mathematics under the Commission on Higher Education, Ministry of Education, Thailand. The author would like to thank the referees for reading this paper carefully and providing valuable suggestions and comments of this paper.

\section{References}

[1] W. R. Mann, "Mean value methods in iteration," Proceedings of the American Mathematical Society, vol. 4, pp. 506-510, 1953.

[2] S. Reich, "Weak convergence theorems for nonexpansive mappings in Banach spaces," Journal of Mathematical Analysis and Applications, vol. 67, no. 2, pp. 274-276, 1979.

[3] H. H. Bauschke, E. Matoušková, and S. Reich, "Projection and proximal point methods: convergence results and counterexamples," Nonlinear Analysis: Theory, Methods E Applications, vol. 56, no. 5, pp. 715-738, 2004.

[4] A. Genel and J. Lindenstrauss, "An example concerning fixed points," Israel Journal of Mathematics, vol. 22, no. 1, pp. 81-86, 1975.

[5] F. E. Browder and W. V. Petryshyn, "Construction of fixed points of nonlinear mappings in Hilbert space," Journal of Mathematical Analysis and Applications, vol. 20, pp. 197-228, 1967.

[6] H. Iiduka and W. Takahashi, "Strong convergence theorems for nonexpansive mappings and inversestrongly monotone mappings," Nonlinear Analysis: Theory, Methods E Applications, vol. 61, no. 3, pp. 341-350, 2005.

[7] T.-H. Kim and H.-K. Xu, "Strong convergence of modified Mann iterations," Nonlinear Analysis: Theory, Methods \& Applications, vol. 61, no. 1-2, pp. 51-60, 2005.

[8] C. Martinez-Yanes and H.-K. Xu, "Strong convergence of the CQ method for fixed point iteration processes," Nonlinear Analysis: Theory, Methods \& Applications, vol. 64, no. 11, pp. 2400-2411, 2006.

[9] K. Nakajo and W. Takahashi, "Strong convergence theorems for nonexpansive mappings and nonexpansive semigroups," Journal of Mathematical Analysis and Applications, vol. 279, no. 2, pp. 372$379,2003$.

[10] X. Qin and Y. Su, "Approximation of a zero point of accretive operator in Banach spaces," Journal of Mathematical Analysis and Applications, vol. 329, no. 1, pp. 415-424, 2007.

[11] G. Marino and H.-K. Xu, "Weak and strong convergence theorems for strict pseudo-contractions in Hilbert spaces," Journal of Mathematical Analysis and Applications, vol. 329, no. 1, pp. 336-346, 2007.

[12] S. Plubtieng and K. Ungchittrakool, "Approximation of common fixed points for a countable family of relatively nonexpansive mappings in a Banach space and applications," Nonlinear Analysis: Theory, Methods E Applications, vol. 72, no. 6, pp. 2896-2908, 2010. 
[13] E. Blum and W. Oettli, "From optimization and variational inequalities to equilibrium problems," The Mathematics Student, vol. 63, no. 1-4, pp. 123-145, 1994.

[14] P. L. Combettes and S. A. Hirstoaga, "Equilibrium programming in Hilbert spaces," Journal of Nonlinear and Convex Analysis, vol. 6, no. 1, pp. 117-136, 2005. 


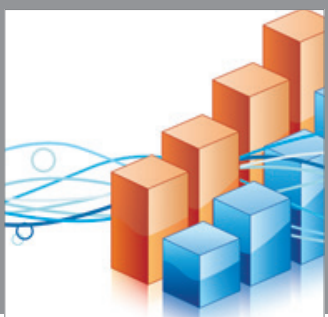

Advances in

Operations Research

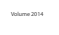

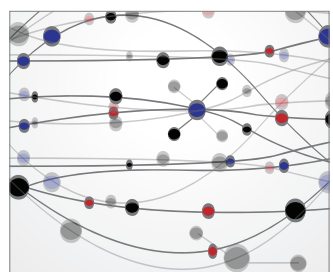

\section{The Scientific} World Journal
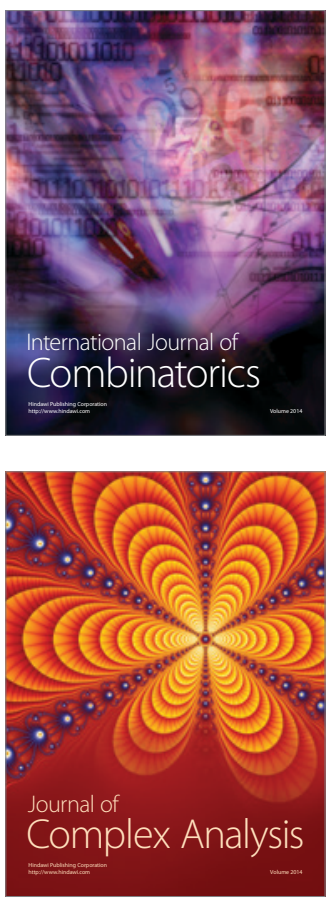

International Journal of

Mathematics and

Mathematical

Sciences
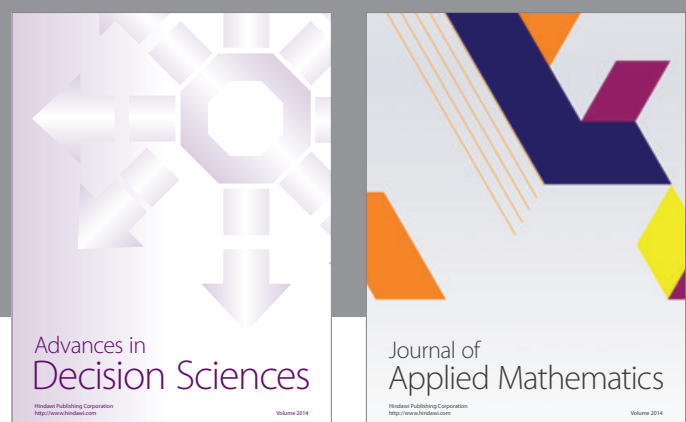

Journal of

Applied Mathematics
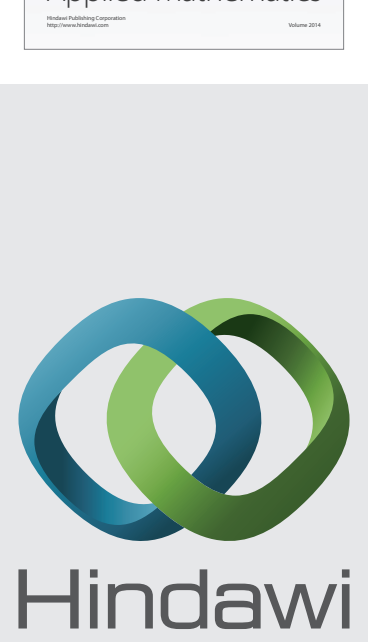

Submit your manuscripts at http://www.hindawi.com
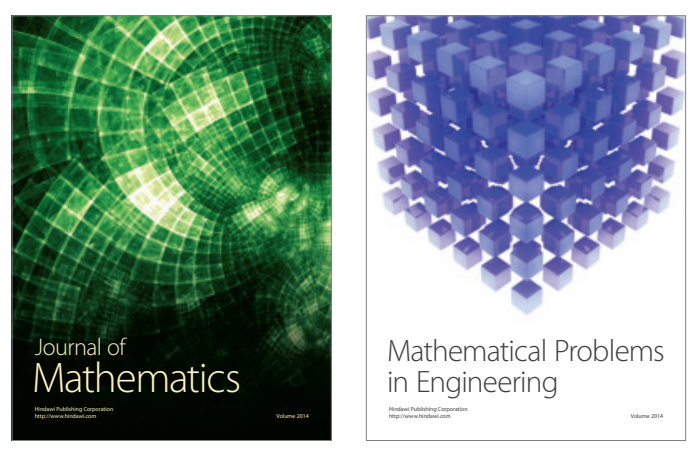

Mathematical Problems in Engineering
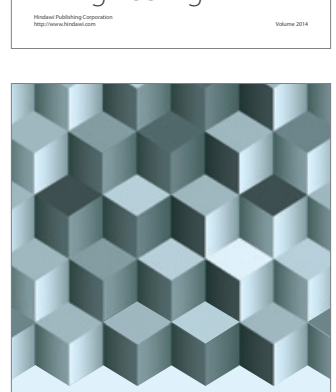

Journal of

Function Spaces
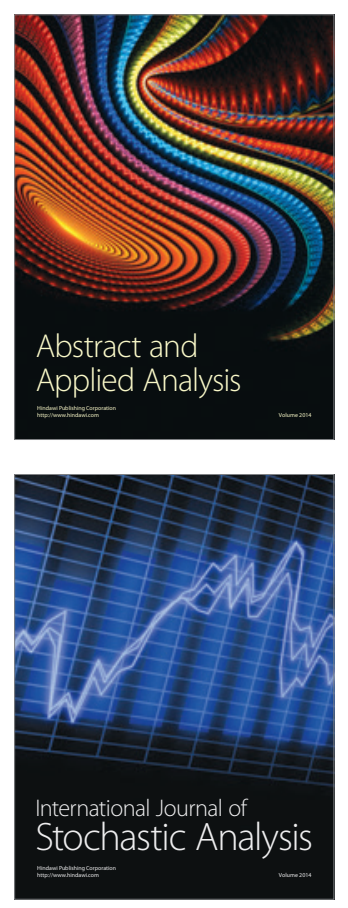

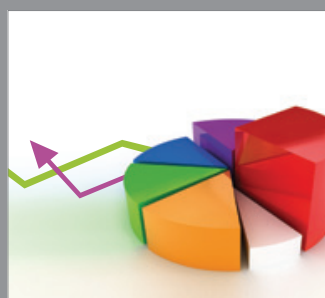

ournal of

Probability and Statistics

Promensencen
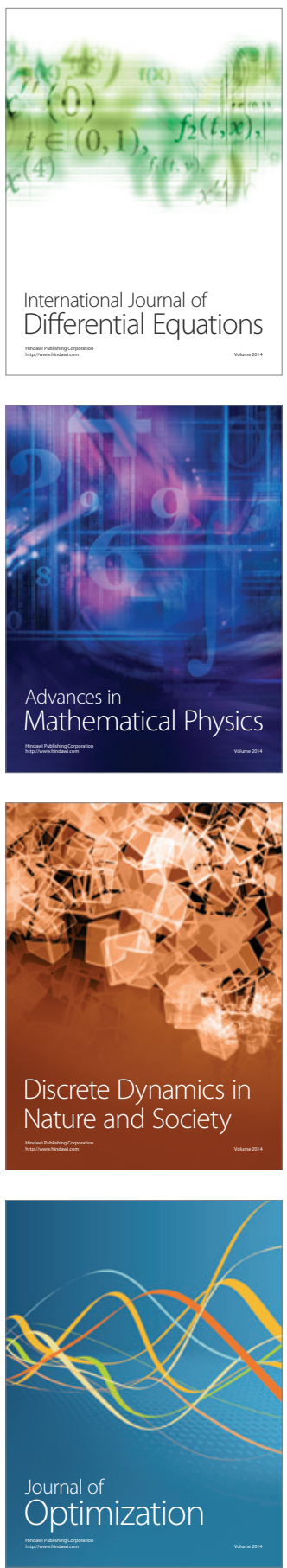